\title{
Reflexiones sobre las áreas naturales protegidas y la legislación ambiental. Caso: el Santuario Nacional del Ampay-Tamburco Apurímac - Perú
}

\author{
Jesús Lizarzaburu Vites*
}

http://dx.doi.org/10.21503/CienciayDesarrollo.2012.v15i1.06

En el Perú tenemos aproximadamente 6,000 normas ambientales; según los expertos en la materia, la gran mayoría de estas normas, son desconocidas por la población; en otros casos los responsables de las instituciones correspondientes no las aplican o no las cumplen; por último, son muy comunes los casos, de tergiversación o mala interpretación jurídica de las normas ambientales.

En el año 1987 es declarado el glaciar Ampay, Santuario Nacional, categoría establecida por Decreto Supremo 042 - 87- AG, con el objetivo de proteger el hábitat, y la especie forestal endémico, llamado "Intimpa" (Podocarpus Glomeratus), único genero de conífera sudamericana.

El Santuario Nacional del Ampay, es la única Área Natural Protegida del departamento de Apurímac. ¿Por qué toma relevancia actual su conservación? En el conjunto de estrategias para reducir los efectos negativos del cambio climático, y adecuarnos a las nuevas condiciones ambientales, se considera entre otros aspectos: el fortalecimiento de capacidades de la población rural; la forestación y reforestación; y la conservación de la diversidad biológica o biodiversidad. Lograr estos objetivos exige introducirnos en la dimensión de la Gestión Ambiental de las áreas naturales protegidas, dentro del marco legal existente.

La ley de Areas Naturales Protegidas Nº 26834 en su artículo 6०. dice lo siguiente: "Las Áreas Naturales Protegidas a que se refiere el Articulo $22^{\circ}$. de la presente ley, conforman en su conjunto el Sistema Nacional de Areas Naturales Protegidas por el Estado (SINANPE), a cuya gestión se integran las instituciones públicas del Gobierno Central, Gobiernos Descentralizados a nivel Regional y Municipalidades, instituciones privadas y las poblaciones locales que actúan, intervienen o participan, directa o indirectamente en la gestión y desarrollo de estas áreas".

Mi primera inquietud es, ¿Cuántas instituciones y organizaciones, de nuestra provincia, participan en la Gestión Ambiental del Santuario Nacional El Ampay? ¿Cuántos sabemos que estamos obligados a participar en su gestión?

Cuando en la ley se enuncia la palabra gestión debemos entender que nos referimos específicamente a la gestión ambiental. ¿Qué es Gestión Ambiental? Llamamos así, al conjunto de acciones y actividades, encaminadas al uso, conservación y aprovechamiento planificado de

\footnotetext{
* Geógrafo: Mg. en Docencia Universitaria. Diplomado en Proyectos de Inversión Pública; Especialista en Planificación Urbana y Regional; Especialista en Gestión del Medio Ambiente. Docente universitario UAP. E-mail: jslizarzaburu512@hotmail.com
} 
los recursos naturales y en general los del medio ambiente. Su implicancia está relacionada a la conservación de ecosistemas frágiles, protección de especies amenazadas, el aprovechamiento cinegético, el manejo ictiológico, la zonificación forestal y de ecosistemas, todo vinculado a la organización de los asentamientos rurales, urbanos e industriales.

La definición de gestión ambiental lleva implícito el objetivo de eficacia, eficiencia y efectividad. El logro de estos objetivos sugiere la aplicación de técnicas, métodos e instrumentos de gestión para el manejo de áreas naturales protegidas; por lo tanto en la gestión ambiental es categórico aprovechar los recursos naturales de modo racional y rentable, aplicando criterios de una economía verde. ¿Y cuanto de esto se hace en nuestra área natural protegida? Nos preguntamos; ¿Cuáles son los instrumentos de gestión que nos permiten un uso, conservación y aprovechamiento planificado en el manejo de las Áreas Naturales Protegidas? Para responder a tal pregunta nos remitimos al Reglamento de la Ley de Áreas Naturales Protegidas, D.S. 038-2001$A G$, en la cual se indica que estos comprenden:

1. El Plan Director

2. El Plan Maestro

3. El Plan de Manejo de Recursos y Plan de Uso Público

4. Los Planes Operativos

5. La Memoria Anual

¿Sabemos cual de estos instrumentos están ya elaborados?, ¿En cuáles, hemos participado? ¿Cómo aportamos al logro de los objetivos planteados?, ¿Qué piensan en la institución en la que estudias o laboras sobre nuestro Santuario Nacional?

Cuando se realiza el ordenamiento territorial de una jurisdicción, sea distrital, provincial o regional los documentos que se generan, como la zonificación ecológica económica, deben considerar necesariamente las áreas naturales protegidas que existen dentro de su jurisdicción.

El Ampay, como montaña del sistema andino, es en esencia un glaciar, porque todo el año mantiene una cobertura de hielo, pero no se encuentra en el registro nacional de glaciares del Perú. La ausencia de este Santuario Nacional en este registro significa no ser beneficiado con los programas de inversiones económicas e investigaciones al más alto nivel técnico relacionados a los procesos de retroceso glaciar. ¿Y esta indiferencia?

El cambio climático como fenómeno global; la desidia de nuestros representantes como tradición política; y un porcentaje del público en general, ha convertido este santuario en un lugar donde el arrojo de desperdicios, las fogatas incendiarias, la extracción vegetal y la cacería, constituyen una reivindicación social de tenebroso y escalofriante futuro para nuestra única área natural protegida. En el periodo húmedo, el peligro de desborde de las lagunas o aluviones es latente; y en el periodo seco, el retroceso glaciar un drama. ¿Es acaso El Ampay, el apu tutelar de la ciudad de Abancay merecedor de esta triste agonía? 